\title{
Forced Exposure and Psychological Reactance: Antecedents and Consequences of the Perceived Intrusiveness of Pop-Up Ads
}

\author{
Steven M. Edwards, Hairong Li, and Joo-Hyun Lee
}

This paper explores forced viewing of "pop-up ads" on the Internet to understand better how viewers come to define ads as irritating and decide to avoid them. Perceived intrusiveness was suggested as the underlying mechanism by which the process occurs. Antecedents of intrusiveness were identified that affect perceptions of ads as interruptions, including congruence of the advertisement content with the current task and intensity of cognition at the moment the ad pops up. The consequences of intrusiveness were shown to be caused by feelings of irritation and ad avoidance. The results provide an understanding of how consumers experience forced exposure situations in interactive environments and highlight implications for advertisers seeking to increase the effectiveness of on-line advertising.

Steven M. Edwards (Ph.D., University of Texas at Austin) is an assistant professor, Department of Advertising, Michigan State University

Hairong Li (Ph.D., Michigan State University? is an associate professor, Department of Advertising, Michigan State University.

Joo-Hyun Lee is a doctoral candidate in the Department of Advertising, Michigan State University.

This research was funded by a grant from the American Academy of Advertising.
Journal of Advertising, Volume XXXI, Number 3 Fall 2002
The idea that, for every action, there is an equal and opposite reaction has been termed reactance in psychology literature. Reactance theory is a social psychological theory that explains human behavior in response to the perceived loss of freedom in an environment (Brehm 1966). Reactance is postulated to be experienced in response to the environment and used to help persons reestablish freedom and control of a situation. When there is a threat to a person's freedom, that person will attempt to restore the freedom by exhibiting opposition or resisting pressures to conform (Brehm and Brehm 1981). Similarly, consumers have been shown to interpret commercial messages actively and react against threats of persuasion to further their own goals. This paper explores Web surfers' reactions when they are forced to view advertising. Reactance may be especially important in light of new advertising delivery techniques developed for the Internet, such as pop-up ads.

The purpose of this research is twofold: First, we investigate what characteristics of pop-up ads are perceived as intrusive. Specifically, the study investigates four aspects of ads themselves that may moderate perceptions of pop-up advertisements as intrusive: timing of the display, duration of the ad, congruence with editorial content, and perceived informational and entertainment value. Second, we hope to understand better the relationship between the antecedents and consequences of ads being perceived as intrusive by examining reactions such as irritation and ad avoidance. We believe that, if the point at which advertising becomes intrusive can be identified, strategies for reducing irritation and the avoidance of advertising can be formulated.

\section{Forcing Exposure to Internet Advertising}

The declining click-through rates of conventional banner ads and rising doubts about Web sites' advertising business models are driving concerned advertisers beyond banner ads. As advertisers scramble to find alternatives, rich media are quickly becoming the standard by which the sophistication of Internet advertising is being judged. Rich media ads contain content created with new technologies (e.g., Java, JavaScript, Macromedia Flash, Macromedia Shockwave, (D)HTML, VRML) and are used to deliver high aural and visual 
impact. Use of rich media is growing at an annual rate of $53 \%$ and is forecasted to reach $\$ 34$ billion by 2004 (Bowen 2001). With the increase in the popularity of rich media ads, new delivery techniques have been developed to solve bandwidth problems associated with larger rich media file sizes.

Pop-ups are one of the popular techniques to deliver rich media ads that are able to contain more sophisticated messages on the Web (Milward Brown Interactive 1999a). According to Interactive Advertising Bureau's (2001) guidelines, pop-ups (formally termed interstitials) refer to a form of rich media ads that "automatically launch in a new browser window when a Web page is loaded." Pop-unders are another form of interstitials that load behind the users' Web browser so that they may be seen after users close the browser window (Taylor 2001). Although different forms of interstitials can be programmed, they are distinct from conventional banner ads in the manner in which they are displayed. Banner ads appear when viewing Web pages, usually at the top or along the sides of the page. Because banner ads are generally displayed on the periphery, they do not interrupt the activity of Web viewers. However, interstitials can be programmed to appear when entering or exiting a Web page, after a certain amount of time on a Web page, or when a link is selected. The window then can be programmed to remain for a predetermined length of time or until the user chooses to close the window.

When faced with interstitials, Web users are interrupted and forced to react to unrequested commercial messages. In some cases, viewers have the option to "zap" the advertisement by closing the pop-up window, but newer interstitial ad formats expand within a Web page and do not offer such an opportunity. Web surfers are forced to view a short commercial message if they wish to see the Web site. In either case, interruptions force users to respond cognitively, affectively, or behaviorally, possibly resulting in either positive or negative outcomes for the advertiser. This type of forced exposure may elicit a viewer's involuntary attention, as described by Kahneman (1973), which would result in positive effects such as greater processing and increased memory for the ad message. Industry studies have shown increases in ad recall, awareness, and purchase intention for interstitials compared with conventional banner ads (Milward Brown Interactive 1999b). However, forced exposure often interrupts a viewer's normal viewing process, and rich media content may cause a delay in downloading due to large file sizes. Both situations could lead to a negative perception of the advertising as intrusive. Although intrusive advertisements may enhance recall, they also may result in negative attitude formation (Ha 1996) or avoidance of the ads altogether (Abernethy 1991). Thus, an important theoretical and practical issue for pop-up ads on-line is how to minimize the negative perceptions while taking advantage of the potential effective benefits.

\section{The Perceived Intrusiveness of Advertising}

In a survey of U.S. consumers, Bauer and Greyser (1968) identify as the main reasons people criticize advertising the annoyance or irritation it causes, which is believed to lead to a general reduction in advertising effectiveness (Aaker and Bruzzone 1985). However, research also indicates that consumers' criticisms of advertising are generally directed at the tactics advertisers employ that make the experience of processing advertising negative, rather than at the institution of advertising itself (Bauer and Greyser 1968; Ducoffe 1996; Sandage and Leckenby 1980). Therefore, developing a better understanding of these "annoying" or "irritating" tactics should allow for the creation of more effective advertisements.

A few studies have identified aspects of advertising that lead to negative feelings. For example, some believe that irritation occurs as a function of the advertising content and level of stimulation. Content that talks down to consumers, is overly exaggerated, or makes confusing statements has been identified as irritating to consumers (Bauer and Greyser 1968). Advertisements that excessively stimulate consumers' senses can also elicit feelings of irritation. Consumers can become overwhelmed if the ads are too long, too loud, or too big (Aaker and Bruzzone 1985; Bauer and Greyser 1968). Consumers may also feel overstimulated when viewing many ads in a short time or seeing a single ad too frequently (Bauer and Greyser 1968). The likely result is a retreat away from the source of irritation, or ad avoidance (Kennedy 1971; Krugman 1983; Park and McClung 1986; Soldow and Principe 1981). Abernethy (1991) finds that consumers often leave the room or change channels to avoid advertising. Others have shown that television viewers simply ignore ads (Clancey 1994; Krugman and Johnson 1991). However, what is not clear is why the same advertising is annoying to some but not all consumers.

A possible explanation for why consumers view only some advertising as irritating is the concept of intrusiveness. Ha (1996) defines intrusiveness as the interruption of editorial content. Because the first objective of advertising is to get noticed, by definition, advertisements seek to interrupt editorial content. By interfering with the goals of consumers, 
advertising effectively limits the number of actions that consumers can take to attain their goals. Consumers must reevaluate their goals to include advertising (acquiesce), or negative reactions are likely to result in the avoidance of advertising in some way. Aaker and Bruzzone (1985) suggest that negative reactions to advertisements occur to the degree that they cause impatience. To the extent that advertisements are recognized as disturbing, negative outcomes such as irritation and avoidance may result (Kennedy 1971; Krugman 1983; Park and McClung 1986; Soldow and Principe 1981). Therefore, though irritation is a possible emotional reaction and avoidance is a potential behavioral outcome in response to intrusive advertising, the perception of an ad as intrusive is something different.

The perception of an advertisement as intrusive should be considered a cognitive evaluation of the degree to which the advertisement interrupts a person's goals. If we define what is intrusive according to the person, advertising itself is not intrusive. Rather, intrusiveness is defined by the degree to which a person deems the presentation of information as contrary to his or her goals (either functional or hedonic). As such, intrusiveness should be considered distinct from the emotional or behavioral outcomes that may result. Therefore, it becomes important to understand the means by which perceptions of intrusiveness can be limited to reduce the negative outcomes that are likely to result.

Pasadeos (1990) finds that, when ads are perceived as valuable (containing useful information), they elicit less irritation and avoidance. According to Ducoffe (1995), advertising value is best understood as an overall representation of the worth of advertising to consumers. Ducoffe's (1995, 1996) studies indicate that ad value is positively correlated with the informativeness and entertainment value of an ad and that both information and entertainment value are essential for communication exchanges between advertisers and consumers. Therefore, the perception of intrusiveness may be affected when an ad offers the viewer either utilitarian or aesthetic value or both. To the degree that advertising does not provide value, it may be perceived as coercive and unwelcome. It is this feeling of intrusiveness that may drive negative reactions toward ads that are recognized as trying to persuade.

\section{Reactance}

Brehm and Brehm (1981) describe attempts to change behavior as involving both persuasion and coercion and believe that the degree to which these attempts intrude on a person's freedom determine that consumer's response. Brehm (1966) terms this feeling reactance and proposes that it occurs to the degree that (1) the behavior threatened is important, (2) the severity of the threat to the behavior increases, (3) the threat affects other freedoms, and (4) the person ever actually enjoyed the freedom. Clee and Wicklund (1980) describe reactance as a boomerang effect in which the perception of coercion is met with an equal but opposite influence, which is used by consumers to restore their freedom of choice. This effect can foster a desire to engage in the threatened behavior even more strongly (rebellion) or can be manifested as an attitude change in the person's belief that the activity is important (acquiescence).

Several studies demonstrate that hard-sell tactics are less persuasive than soft-sell tactics (Clee and Wicklund 1980; Reizenstine 1971), and Brehm and Brehm (1981) point out that hard-sell messages reveal the intent of the persuader and therefore should be met with greater resistance. Robertson and Rossiter (1974) find that perceptions of persuasion correlated with less favorable attitudes toward the product being sold. To the degree that advertisements are recognized as simply attempts at persuasion, they could evoke a mild form of reactance.

Although perhaps not as strong as other forms of direct coercion, advertisements may be perceived as an interruption and elicit a similar feeling. To the degree that radio listeners are enjoying music, the threat of advertising may result in channel surfing to regain the freedom to listen to music. To the degree that the option of changing stations is taken away or all stations are playing ads at the same time, increased psychological reactance should be manifest against the interruption (advertising) and perhaps radio stations themselves. Multiple theories of media interactions indicate that consumers are wary of persuasion. Consumers actively interpret the techniques that ads use to persuade (Friestad and Wright 1994) and form counterarguments against ad claims when they are highly involved (Petty and Cacioppo 1979), all in an effort to defend themselves or react against persuasive messages.

If consumers' reactions to advertising are defensive, it may not be an effective strategy to force them to view advertisements. Reactance theory would dictate that forced exposure will result in negative consequences for advertisers; however, not all forced advertising may be unwelcome. Discovery of the means by which reactance can be minimized may increase the efficacy of advertising that has the potential to threaten viewers' perceptions of freedom. 


\section{Hypotheses}

As has been argued, intrusiveness can be thought of as a psychological consequence that occurs when an audience member's cognitive processes are interrupted and that may result in the avoidance of advertising. However, advertising may not always be perceived as equally intrusive. Perceived intrusiveness may be moderated by the intensity or focus of a cognitive process. By the intensity of a cognitive process, we mean the degree to which an audience is mentally engaged in an activity, not cognition itself. For example, a television commercial would be more intrusive when inserted in the middle of a highly involving show than at the end of a less arousing program. Similarly, the timing of exposure to rich media ads during normal surfing sessions on the Web may differentially affect perceptions of intrusiveness. For example, viewers' cognitive intensity is likely to be higher when they are viewing a content page than when taking a cognitive pause to switch pages. Similarly, cognitive intensity should be higher when taking a cognitive pause to switch pages than when finished surfing and closing the browser. Therefore, an ad displayed under different cognitive loads may be perceived as different in terms of intrusiveness. We hypothesize that

H1a: Ads that interrupt content pages will be perceived as more intrusive than will ads displayed between breaks in content pages.

$\mathrm{H} 1 \mathrm{~b}$ : Ads displayed between breaks in content pages will be perceived as more intrusive than will ads displayed upon closing the browser.

Similarly, the duration of the interruption may affect the perceived level of intrusiveness. The longer an interruption, the more intrusive it may be perceived to be. Theoretically, extended interruptions should be perceived as greater threats to freedom than should shorter interruptions, which should result in greater psychological discomfort and greater reactance. Therefore,

H2: Longer ads will be perceived as more intrusive than will shorter ads in forced exposure situations.

Holding the intensity of cognition constant, there may be other aspects of advertisements that moderate the perception of intrusiveness. Persuasion attempts are not always perceived as intrusive and met with skepticism, counterarguments, or source derogations; they can be met with support arguments (Petty and Cacioppo 1979). Advertisements often provide relevant information and/or consumer gratifica- tions, such as escapism, diversion, esthetic enjoyment, or emotional release (McQuail 1983). This psychological force, in opposition to reactance, has been termed positive social influence. Clee and Wicklund (1980) posit that persuasive communications elicit both reactance and positive social change and that the net result of any persuasive communication must take into account both forces. Given the existence of a positive social interpretation of persuasive communication, the degree to which viewers perceive benefits or gratifications from persuasion attempts should counter the perception of intrusiveness.

One possible positive social influence that may affect the perception of intrusiveness is the perceived value of an advertisement. More specifically, perceived intrusiveness may be lessened for ads that are deemed of high value. When faced with advertising on-line, users may regard the degree of congruity between the advertising content and the editorial content as valuable. For example, exposure to advertising for Chevrolet while surfing the Internet for information about a new car purchase would probably be perceived as less intrusive than would an ad for Microsoft in the same situation. Ads that are congruent with expectations and/or current cognitive activities could be perceived as positive social influences and thus not be considered threats to the consumer's freedom. In contrast, ads not congruent with expectations activate divergent knowledge structures and create added mental processing demands. These added demands threaten the freedom to continue with current processing activities and may result in considerable reactance. Therefore,

H3: Ads that are congruent with the editorial content will be perceived as less intrusive than ads that are not congruent.

H4: Ads that are congruent with the editorial content will be perceived as more informative than ads that are not congruent.

H5: Ads that are perceived as more informative will be rated as less intrusive than ads that are perceived as less informative.

A second positive social influence identified by Bauer and Greyser (1968) and Ducoffe (1995) is entertainment. To the degree that advertisements are perceived as entertaining, they should provide value to the viewer. To the degree that the entertainment is welcome, it should not be perceived as interrupting the cognitive goals of the viewer, and, therefore, it should garner less psychological reactance than advertising judged less entertaining. Thus, it is expected that

H6: Ads that are perceived as more entertaining will be rated as less intrusive than ads that are perceived as less entertaining. 
As reviewed previously, theories of psychological reactance suggest that, in response to a loss of freedom, viewers will feel uncomfortable and attempt to regain control of their experience. When advertising interrupts the goals of consumers, consumers are likely to seek their freedom either passively, by ignoring the interruption (Clancey 1994; Krugman and Johnson 1991), or actively, by dispensing with it (Abernethy 1991; Speck and Elliott 1997). The degree to which viewers seek freedom will be directly proportional to the perception of the ad as an intrusive threat to that freedom. The perception of the intrusiveness of an ad will likely result in feelings of irritation and ultimately the avoidance of that ad, if possible. Therefore, perceived intrusiveness, level of irritation experienced, and avoidance behaviors should all be related. On the basis of the reviewed literature, we believe that

H7: The perception of intrusiveness will be positively related to feelings of irritation.

H8: The perception of intrusiveness will be positively related to advertising avoidance.

H9: Feelings of irritation will be positively related to advertising avoidance.

\section{Methods}

\section{Participants}

A total of 379 participants was recruited from undergraduate courses at a Midwestern U.S. university to participate in the experiment. The courses were campuswide electives, so the participants represented a variety of majors and backgrounds. Women constituted $58 \%$ of the sample, men $42 \%$.

\section{Experimental Design}

The experiment used a $2 \times 2 \times 3$ factorial design in which participants were asked to find out as much information as they could about either financial aid or current movies using a Web site provided. The three independent variables manipulated were editorial-ad congruence, duration of interruption, and intensity of cognition when faced with a pop-up ad. Two conditions of editorial-ad congruence were created by placing a pop-up ad for a movie on either a site that featured movie reviews or a site that featured financial aid information. When an interstitial was incongruent, it was assumed to be more intrusive than when the advertisement was congruent with the site content. Duration of interruption of the interstitial was manipulated by providing content that lasted either 10 or 20 seconds. Although participants could close the interstitial at will, it was assumed that a longer interstitial would be more intrusive than a shorter one if watched entirely.

Cognitive intensity of the viewer when seeing the interstitial on a Web site was the third independent variable. In the first condition, an interstitial was programmed to pop up 20 seconds after the experimental page was opened. The experimental pages for either movie reviews or financial aid were pretested and took more than two minutes to read. This condition was designed to be the most intrusive, as it interrupted participants at a time they were actively processing information that was needed to complete the assigned task. In the second condition, the same content as appeared in the first condition was positioned on two Web pages with the interstitial placed between them. The ad opened only when the participants chose to move from the first to the second page. Providing participants the opportunity to take a "cognitive pause" from their reading was designed to reduce the level of intrusiveness felt in response to the advertisement. Participants had to request the second page of information, thereby giving them more control over the situation. The third condition was similar to the first condition, but the interstitial was shown only when the participants finished reading the articles and exited the experimental page. By placing the advertisement at the end of the task, participants were no longer actively processing the information at the Web site and therefore should not have experienced reactance.

\section{Experimental Stimuli}

Two Web sites were created for the experiment: one site contained movie reviews and the other financial aid information. The site themes were selected from a pretest in which 16 topics were rated for student interest. The selected topics were rated as moderately interesting by a sample of both male and female students $(n=35)$ who did not participate in the main experiment. The content was adapted from existing Web sites. All experimental conditions were identical in structure, font size, color, and the number and length of the articles. The movie review site reviewed the movies Beautiful and Cyberworld $3 D$, and the financial aid site contained articles about "Stafford Loans" and "Loan Consolidation."

Two interstitials (created using Macromedia Flash) advertised a fictitious movie titled The Good Days. Both interstitials had identical format and content and varied only in length. The 20 -second interstitial 
Table 1

Scale Reliabilities

\begin{tabular}{lccc}
\hline \hline Variable & Indicators & Alpha & $N$ \\
\hline $\begin{array}{l}\text { When the ad popped-up, I thought it was... } \\
\text { Perceived intrusiveness }\end{array}$ & $\begin{array}{l}\text { distracting, disturbing, forced, interfering, intrusive, } \\
\text { invasive, and obtrusive }\end{array}$ & .91 & 373 \\
& irritating, phony, ridiculous, stupid, and terrible & .87 & 373 \\
Perceived irritation & & & \\
The movie ad / saw was... & helpful, unimportant, uninformative, and useless & .82 & 370 \\
Informativeness & attractive, enjoyable, entertaining, and fun to watch & .94 & 371 \\
Entertainment &
\end{tabular}

used blank filler frames to maintain the same amount of information as the 10 -second interstitial. Both interstitials were sized $350 \times 350$ pixels and set to pop up in the center of the computer screen. Specifically, the ads contained four still pictures representing the movie scenes, a soft piano as background music, and a listing of a fictitious title, director, and cast of the movie.

\section{Procedure}

Participants were randomly assigned to 1 of the 12 conditions (2 levels of editorial-ad congruence, 2 levels of duration, and 3 levels of cognitive intensity) and asked to read an instruction page about the experiment. To stimulate interest in the Web content, participants were told they would be tested about the site content at the end of the viewing session and that the person who answered the most questions correctly would win a cash prize. Participants viewed the Web pages individually and were fitted with earphones to hear the music used in the ad. The ads were programmed to remain for either 10 or $20 \mathrm{sec}-$ onds, but participants were able to close the interstitials at will and continue with their assigned task. After the 10-minute viewing session was over, each participant was asked to quit the Web browser and fill out a questionnaire and then was debriefed.

\section{Measures}

A questionnaire was used to assess perceived intrusiveness, irritation, perceived informativeness and entertainment value of the movie ad, and the demographics of the participants. All items were answered using seven-point scales with response categories from strongly agree to strongly disagree. The intrusiveness measure consisted of seven items: distracting, disturbing, forced, interfering, intrusive, invasive, and obtrusive (Li, Edwards, and Lee 2001). Irritation was measured using five items: irritating, phony, ridiculous, stupid, and terrible (Wells, Leavitt, and McConville 1971). The perceived informativeness and entertainment value of the interstitial were measured using modified scales based on the work of Ducoffe (1996). Both informativeness (helpful, unimportant, uninformative, and useless) and entertainment value (attractive, enjoyable, entertaining, and fun to watch) were measured using four items. Finally, ad avoidance was measured using observational data. Participants' actual time spent viewing the ad was assessed using screen capture software and later coded for analysis. Although each of the measures had been used in previous studies, a confirmatory factor analysis of the items was conducted to investigate their validity in this context. Specifically, the measured constructs (intrusiveness, irritation, advertising entertainment, and advertising informativeness) were tested using first-order confirmatory factor models in which every item was confined to load on its specified factor. In all the models, the item-loading estimates on their prespecified factors were highly significant $(p<.001)$, and goodness-of-fit indices demonstrated the quality of the measurement models (intrusiveness: goodness-of- fit index $[\mathrm{GFI}]=.984$, adjusted goodnessof-fit index $[\mathrm{AGFI}]=.965$; irritation: $\mathrm{GFI}=.997$, $\mathrm{AGFI}=.960$; advertising entertainment: $\mathrm{GFI}=.998$, AGFI=.990; advertising informativeness: GFI=.993, AGFI=.963). The questions asked and response items that make up each measure, along with reliability coefficients, are presented in Table 1.

\section{Results}

\section{Manipulation Checks}

To assess the validity of our manipulations, a third sample of 60 undergraduate students was randomly 
assigned to 1 of the 12 conditions in the main experiment and asked to assess the perceived congruence of the ad with the task, the perceived length of the ad, and the intensity of cognition at the moment the ad appeared. To check the manipulations of our independent variables, we first examined the degree to which participants recognized the editorial congruence of the ad. Participants were asked to agree or disagree with statements regarding the degree to which the ad helped them fulfill their task, provided useful information, and was relevant to their task on a seven-point scale. Those who saw a congruent ad reported significantly greater relevance $(\mathrm{x}=3.16)$ than did those who saw a noncongruent ad $(\overline{\mathrm{x}}=2.31), \mathrm{t}_{t 588}=2.49, p<.05$.

To assess if the length of the ads was recognized, participants were asked to agree or disagree with statements such as the ad was short, seemed to play for a long time, and was over before I knew it. There was no significant difference between those who saw a 10 -second ad $(\bar{x}=2.86)$ and those who saw a 20 second ad $(\bar{x}=2.68), p>.05$. Therefore, participants perceived the ads to be of similar length, which indicates the failure of our manipulation.

Finally, participants' levels of cognitive intensity at the moment the ads popped up were assessed. Participants reported that they were more involved with the article, more actively reading the information presented, and more focused on the article when an ad popped up while they were reading the text $(\vec{x}=5.20)$ than if it appeared between pages $(\overline{\mathrm{x}}=3.97)$ or upon exiting the browser $(\overline{\mathrm{x}}=3.87), \mathrm{F}_{12,57}=4.71, p<.05$. Post hoc analyses revealed significant differences in cognitive intensity when participants were reading the text compared with when they were between pages or exiting the browser. There was no significant difference reported for between pages and exiting the browser. The manipulation resulted in only high and low levels of cognitive intensity, and, therefore, no further distinction was made between the manipulations that resulted in similar levels of cognitive intensity.

To conduct an overall assessment of the degree to which these variables may have elicited reactance, we measured perceptions of the ad as threatening freedom. The 60 participants were asked to rate the degree to which they felt their freedom was threatened, that the ad infringed on their freedom, and that the ad forced them to respond. In contrast to expectations, those who saw a task-relevant ad reported a greater threat to freedom $(\bar{x}=3.07)$ than did those who saw a nonrelevant ad $(\overline{\mathrm{x}}=2.48), \mathrm{F}_{(1,48)}=3.73, p<.05$. However, similar to the findings pertaining to the perceived duration of the ad, participants viewing a 10 -second ad experienced a similar amount of reac- tance $(\bar{x}=2.64)$ as did those viewing the 20 -second ad $(\overline{\mathrm{x}}=2.90), p>.05$. Participants who saw an ad within a page reported greater reactance $(\bar{x}=3.32)$ than did those who saw an ad between pages $(\bar{x}=2.83)$, who reported greater reactance than did those who saw an ad when exiting the browser, $\mathrm{F}_{2,48}=4.78, p<.05$. In summary, though the manipulations of editorial-ad congruence and cognitive intensity adequately distinguished between conditions, the strength of the reactance was only mild. That is, advertising may not warrant strong feelings about the loss of control. Editorial-ad congruence was recognized as congruent or not congruent to the assigned task, as anticipated, but ratings of the threat to freedom were opposite expectations. This finding may indicate that, when ads are relevant, they elicit greater attention and are perceived as greater threats to freedom than when not relevant. If true, the value that ads provide by being relevant must overcome the perceived threat to freedom to be perceived as unintrusive. Finally, the manipulation to change the perception of the duration of the interruption was unsuccessful and not expected to explain variance in the proposed model.

\section{Model Testing}

We tested the 10 hypotheses using structural equation analysis with Amos 4.0. The promise of such an approach lies in that, when tested simultaneously, existing relationships between constructs may change and additional relationships may emerge. Structural equation modeling (SEM) captures these changes and thus provides a better description of the relationships among variables (Bollen 1989).

All constructs described in the hypotheses and shown in Figure 1 were specified in the initial model. Exogenous variables included cognitive intensity, duration of the interruption, and editorial congruence. Each was a manipulated variable and therefore categorical in nature. Although not ideal for SEM analysis, categorical variables can be successfully incorporated into such analysis (Jöreskog and Sörbom 1989). The variables were coded so that higher values reflect greater cognitive intensity, longer duration, and greater congruence. Five endogenous variables included ad informativeness, ad entertainment, ad intrusiveness, ad irritation, and ad avoidance. These are each observed, continuous measures. The maximum likelihood method was used in model estimation. The initial analysis indicated a poor fitting model, $\chi^{2}=668.09(\mathrm{~d} . \mathrm{f}=244)$, a GFI of .87 , AGFI of .84 , comparative fit index (CFI) of .92, and root mean squared error of approximation (RMSEA) of .07. 
Figure 1

A Conceptual Model of the Perceived Intrusiveness of Pop-Up Ads

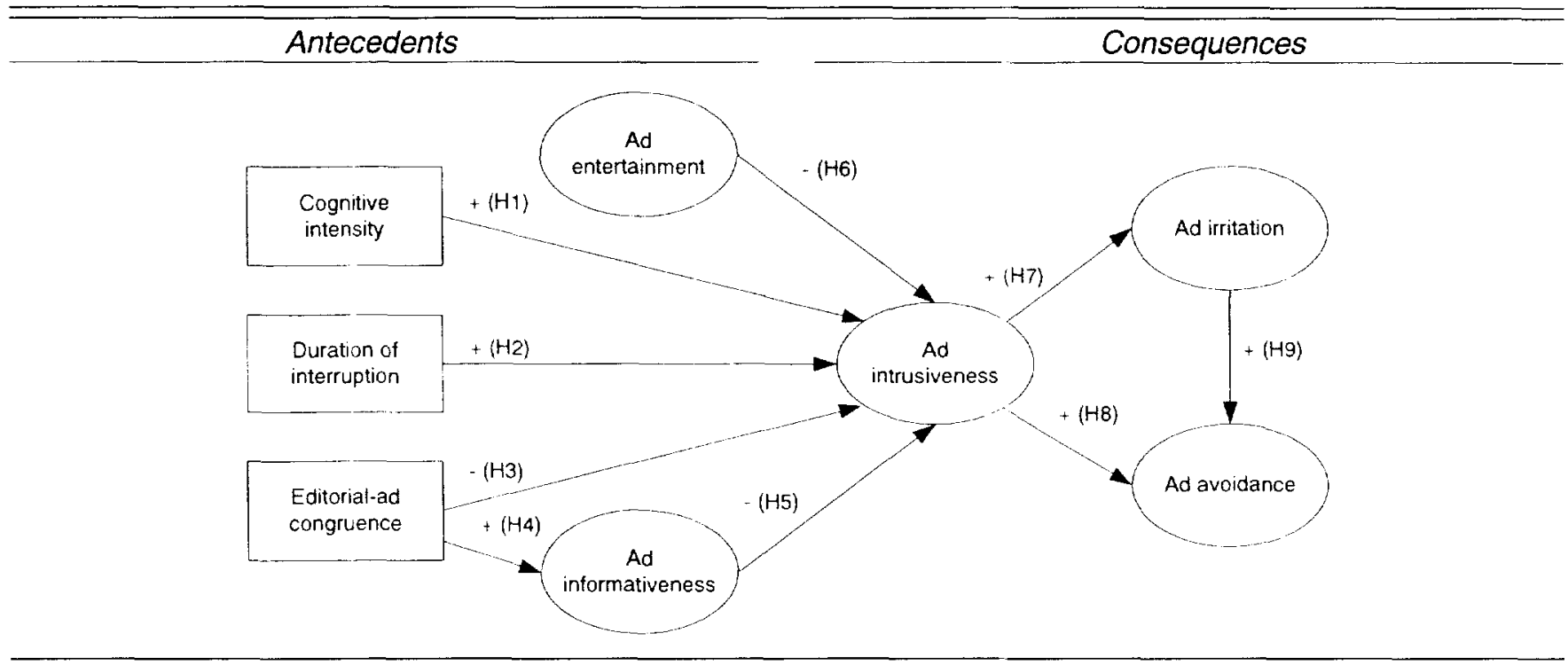

Figure 2

Antecedents and Consequences of Perceived Intrusiveness: The Final Model

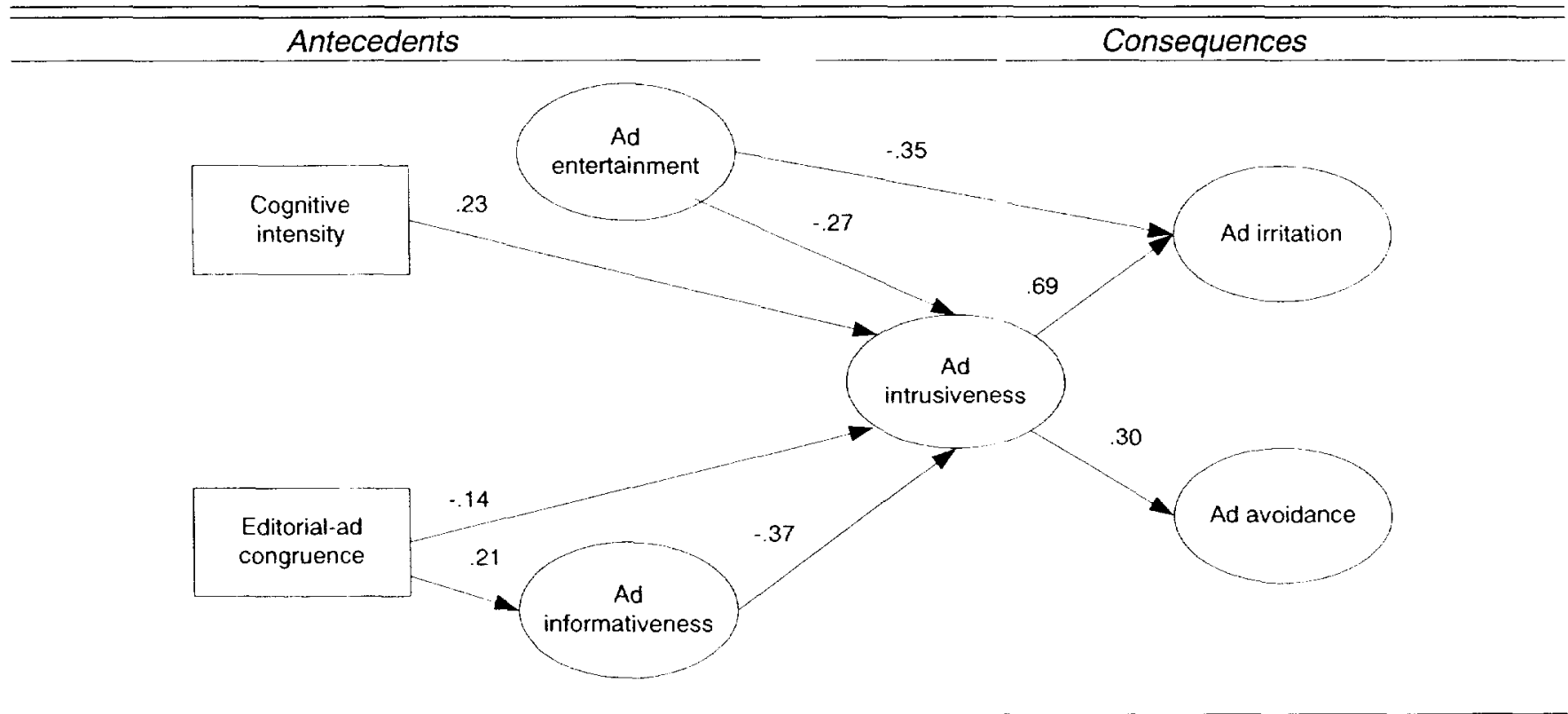

To improve the model, the significance of the regression weights was first examined for all variables. As expected on the basis of the nonsignificant findings of the manipulation check, the perceived duration of the interruption caused by the ad was not significantly related to perceived intrusiveness, $p>.05$. Unexpectedly, irritation did not significantly predict ad avoidance, $p>.05$. Instead, avoidance was driven by the perceived intrusiveness of the ad. Therefore, duration of the interruption was removed from the model, as was the link between irritation and ad avoidance. The revised model was further tested, and modification indices were used to identify any missed relationships in the original model. The degree to which an ad was rated as entertaining was shown to be related to the level of irritation experienced $(p<.01)$ 
Table 2

Final Model Summary

\begin{tabular}{|c|c|c|c|c|c|}
\hline & $\begin{array}{l}\text { Independent } \\
\text { Variables }\end{array}$ & $\begin{array}{c}\text { Dependent } \\
\text { Variables }\end{array}$ & $\begin{array}{c}\text { Unstandardized } \\
\text { Parameters }\end{array}$ & $\begin{array}{l}\text { Standard } \\
\text { Errors }\end{array}$ & $\begin{array}{c}\text { Standardized } \\
\text { Parameters }\end{array}$ \\
\hline $\mathrm{H} 1$ & Cognitive intensity & Ad intrusiveness & -.631 & .129 & -.233 \\
\hline $\mathrm{H} 2^{\star}$ & Duration of interruption & Ad intrusiveness & & & \\
\hline $\mathrm{H} 3$ & Editorial-ad congruence & Ad intrusiveness & .362 & .124 & .141 \\
\hline $\mathrm{H} 4$ & Editorial-ad congruence & Ad informativeness & -.470 & .131 & -.205 \\
\hline H5 & Ad informativeness & Ad intrusiveness & -.416 & .066 & -.373 \\
\hline $\mathrm{H} 6$ & Ad entertainment & Ad intrusiveness & -.305 & .057 & -.273 \\
\hline Added & Ad entertainment & Ad irritation & -.324 & .041 & -.350 \\
\hline $\mathrm{H} 7$ & Ad intrusiveness & Ad irritation & .567 & .049 & .688 \\
\hline $\mathrm{H} 8$ & Ad intrusiveness & Ad avoidance & -2.978 & .533 & -.297 \\
\hline $\mathrm{H} 9^{\star}$ & Ad irritation & Ad avoidance & & & \\
\hline
\end{tabular}

Goodness-of-Fit Indices

$\chi^{2}$

Jöreskog-Sörbom goodness-of-fit index (GFI)

Adjusted goodness-of-fit index (AGFI)

Comparative fit index (CFI)

Root mean square error of approximation (RMSEA) $433.64(\mathrm{~d} . \mathrm{f}=202), p<.001$

.91

.89

.95

.06

*Dropped in the final model.

and therefore was added to the model. Although we expected this relationship to be moderated by intrusiveness, much of the literature on irritation points out that irritation occurs when ads contain untruthful or confusing content or are executed poorly (Aaker and Bruzzone 1985; Bauer and Greyser 1968). The model with the addition of the new causal path between entertainment and irritation was tested, and one item (irritation) from the irritation scale with excessive covariance was removed. The resulting model, presented in Figure 2, was found to fit the data well, $\chi^{2}=433.64$ (d.f. $=202$ ), GFI=.91, AGFI=.89, CFI $=.95$, and RMSEA $=.06$. The significance of regression weights was examined for all remaining constructs, and their associated measures and all relationships were found to be significant at $p<.01$. A final model summary is presented in Table 2 .

The final model provides support for seven of the ten hypotheses. In addition, a new causal relationship (ad entertainment $\rightarrow$ ad irritation) emerged and was added to the model. This addition is conceptually sound, in that previous studies have shown that entertaining ads are perceived as valuable by audiences (Alwitt and Prabhaker 1992; Biel and Bridgwater 1990; Ducoffe 1996). To the degree that viewers are entertained by ads, they are less likely to be irritated. All relationships in the final model seem reasonable and are in accordance with the literature reviewed.
Specifically, two manipulated variables-cognitive intensity and editorial-ad congruence-had a significant impact on perceived intrusiveness, whereas duration of the ad did not. That is, ads were found to be more intrusive by participants highly immersed in the content $(\bar{x}=4.42, \mathrm{~S}=1.41)$ than by those who were less cognitively engaged $(\bar{x}=3.70, S=1.41), t_{(374)}=4.70$, $p<.001$. The manipulation of cognitive intensity specified in $\mathrm{H} 1 \mathrm{~b}$ did not work and therefore could not be tested. However, evidence for $\mathrm{H} 1 \mathrm{a}$ was found. Unfortunately, $\mathrm{H} 2$ could not be supported. The duration of both 10 - and 20 -second ads was perceived similarly, and, thus, duration is not related to perceptions of intrusiveness, $p>.05$. Perhaps the existence of the interstitial itself triggered feelings of intrusiveness, and once a participant decided to watch the ad, the length might have not mattered. Editorial congruence was found to have a negative relationship with perceptions of intrusiveness, and, therefore, $\mathrm{H} 3$ was supported. Ads were perceived as less intrusive when related to the participant's task $(\bar{x}=3.64, \mathrm{~S}=1.42)$ than when not related to the task $(\bar{x}=4.24, S=1.43)$, $\mathrm{t}_{(374)}=4.04, p<.001$. Editorial congruence also had a positive impact on the perception of the ad as informative, in support of $\mathrm{H} 4$. Those who saw the congruent ad reported it to be more informative $(\bar{x}=4.17$, $\mathrm{S}=1.32$ ) than did those who saw the noncongruent ad $(\overline{\mathrm{x}}=3.77, \mathrm{~S}=1.15), \mathrm{t}_{i 3711}=3.14, p<.01$. 
Hypotheses 5 and 6 were related to the degree to which ads that are perceived as informative and entertaining reduce perceptions of the ad as intrusive. Both variables were negatively related to perceptions of intrusiveness, indicating that the more value (information or entertainment) perceived in an ad, the less intrusive it is perceived. Both hypotheses are thus supported. Hypothesis 7 proposed a connection between perceptions of intrusiveness and feelings of irritation. A strong positive relationship was found in support of the relationship. However, the added relationship between the perception of an ad as entertaining and feelings of irritation now means that entertainment has both a direct and an indirect effect on irritation. Hypothesis 8 specified that perceptions of intrusiveness would be positively related to the avoidance of the ad. The model shows that avoidance is caused by the degree to which an ad is judged to be intrusive. Finally, the lack of support for H9 is interesting because feelings of irritation were not significantly related to ad avoidance. Similar to the findings of Cronin and Menelly (1992), this suggests that ad avoidance may take place upon recognition of the ad as intrusive, even though the viewer is not yet irritated.

\section{Discussion}

The current study provides evidence that, when ads are perceived as intrusive, feelings of irritation are elicited and advertisements are avoided. Apparently, perceptions of interstitials as intrusive are related to the level of cognitive intensity with which viewers pursue their goals. When viewers are focused, they perceive interruptions as more severe than when they are not focused. However, through creative advertisement placement strategies, perceptions of intrusiveness may be moderated. When ads are requested or provide value, either in the form of information or entertainment, they are perceived as less of an interruption, are less irritating, and may be less likely to be dismissed as nuisances.

The variables found to limit perceptions of intrusiveness involve (1) targeting viewers when their cognitive effort is low, (2) increasing the relevancy of the advertising, and (3) providing value to viewers. First, strategies that seek to minimize the interruption of viewers' current activities are likely to meet with less resistance. Therefore, viewers should be exposed to pop-up ads only at breaks in content. In the current study, switching between pages offered such a break. However, Web pages could be designed with pictures or large banner ads separating sections of content, thereby providing the breaks needed to launch pop- up ads. Recent practices in the on-line advertising industry to use pop-unders or interstitials (ads that appear in the main Web browser when users attempt to move from one page to another) would be justified by the findings from the current study.

Second, another means of limiting perceptions of intrusiveness involves increasing the relevancy of popup advertisements by using content placement strategies. Although increasing relevance was found to increase reactance, participants actually reported feeling less intrusiveness. A possible explanation for this finding is that relevant ads could not be as easily discounted as meaningless. So, though they raised significantly greater reactance than nonrelevant ads, meaningful information tempered feelings of intrusiveness and irritation. This finding highlights the importance of content placement strategies, which have been used in print media (Janiszewski 1990; Yi 1990) and television (Murry, Lastovicka, and Singh 1992; Park and McClung 1986; Singh and Churchill 1987; Soldow and Principe 1981). The same rationale is being used on-line (Sherman and Deighton 2001). If consumers are surfing "cars.com" and an automobile ad is seen, it is likely to be more relevant than an ad for Budweiser and thus less likely to elicit feelings of intrusiveness and irritation.

Third, the final strategy to reduce intrusiveness is to increase the value viewers receive from ads. Information deemed important or interesting or an ad that is entertaining rewards the viewer, who is thereby less likely to feel irritated by the interruption. Through strategic use and placement of commercial messages, resistance of consumers can be lessened, which is likely to result in less irritation and greater message effectiveness.

However, there are several limitations to the current study that should be addressed. First, the manipulation of ad length was not perceived to differ among participants. Therefore, we cannot comment on previous claims that longer ads are more intrusive or irritating than shorter ads. Subjects had a modicum of control during the experiment, in that they could close the pop-up ad at will. Although participants exposed to the 20 -second ad left the ad open significantly longer than did those exposed to the 10second ad, there was no perceived difference in the length of the ads. Perhaps the participants were not in a hurry to complete the task and therefore did not deem the length of the pop-up ad important. Alternative procedures could include providing an incentive for timely completion of the task or choosing very short and very long ads to maximize perceptions of ad length.

Second, the degree to which participants felt in control of the timing of the appearance of the ad may 
be a limitation. Participants in the "timed" cognitive intensity condition had no control over when the ad popped up, whereas participants in the second and third conditions were required to click a link (either to go to the next page or close the browser) before the ad popped up. Because of the importance of control in assessing perceived interactivity, teasing out the effects of control from cognitive intensity seems like an important next step in this line of research.

Third, the use of categorical exogenous variables in the tested SEM is unorthodox. Although acceptable analytically, cognitive intensity, duration of the interruption, and editorial congruence were manipulated to create experimental conditions and therefore limited the variation and explanatory power of the model. Future research should note this limitation and measure perception's of such manipulations to facilitate greater explanation with continuous exogenous variables.

\section{Conclusion}

We have provided a framework for understanding negative responses to Internet advertising, such as feelings of irritation and ad avoidance. The proposed model is an initial step in understanding the relationships among intrusiveness, irritation, and ad avoidance in forced exposure situations. The proposed model offers several unique characteristics, in that it conceptualizes the role and nature of intrusiveness in understanding responses to advertising and demonstrates that perceptions of intrusiveness may be moderated by other factors. None of these issues has received explicit attention in previous literature. By bringing them together in a framework, we aim to guide future empirical research and theoretical work.

It must be noted that our findings cannot be generalized to all Web site viewing behaviors. This study examines the impact of perceived intrusiveness in the context of task-oriented, extrinsically motivated behavior. Participants were assigned to learn as much as possible about their given tasks, and thus, the motivation underlying the Web surfing task may limit the generalizability of the results. Intrinsically motivated, task-oriented surfing behaviors could be examined by providing participants with a range of topics from which to select. Intrinsically motivated behavior could result in more or less reactance, depending on the strength of the motivation. Therefore, it would be interesting to examine the relationship among motivation, cognitive intensity, and the perception of intrusiveness.

It should also be noted that not all Web site viewing behavior is task- or goal-oriented. Hoffman and Novak
(1996) distinguish goal-directed behavior from experiential or ritual behavior on the Web. Whereas the former refers to activities such as information seeking and on-line shopping, the latter is less directed. Because intrusiveness has been defined as the interruption of cognitive processing, it would be worthwhile to investigate the effects of intrusiveness during experiential behavior. For example, when users are mindlessly surfing through various Web sites without any specific purposes, an interstitial may cause less intrusiveness than it does in a goal-directed context.

Unlike many Web sites with interstitials, only one interstitial popped up at the experimental Web site. Future studies may wish to examine multiple interstitials and vary the frequency with which ads pop up; their cumulative effects may exacerbate perceptions of intrusiveness. The type of message displayed in a pop-up ad may also interact with the act of popping up itself. Static banners may not provide the entertainment that rich media can offer. Alternatively, some consumers may be irritated by having to wait for rich media and prefer a simpler message.

In a similar vein, the method of placing ads in Web sites should be investigated in more depth. The current study manipulates cognitive intensity by placing the ad at different locations within the Web page: at the beginning, in the middle, and at the end. However, technological advances provide many more options for specifying ad placement. These different placements vary in the degree of forced exposure. For example, pop-unders can be loaded under the browser and be seen upon closing the browser. Ads can also be made to float on the browser window without disappearing, be full-screen ads that prevent people from viewing other content, or have the appearance of traditional banner ads but expand without leaving the current Web site. Other ads are programmed to appear only when users wait for the Web pages to load. These diverse tactics and new technologies are allowing for greater control over advertising placement, and it will be necessary to test how people perceive those new ad formats.

A third area that needs to be addressed in future research is the trade-off between good and bad exposure. The old saying that "any publicity is good publicity" illustrates this point. Even if viewers respond negatively to forced exposure advertisements, they are still exposed to the message. This exposure is likely to elicit increased levels of attention and should facilitate memory for the advertisement. Therefore, it becomes important to consider the goal of the campaign when studying about the effects of intrusiveness. For example, advertisers seeking positive 
attitude formation as a campaign objective may wish to avoid intrusive ads, which are likely to result in irritation. However, if recall or recognition is a goal, intrusive ads could be more effective than nonintrusive ads. Exploration of the relationship between intrusiveness and memory is needed to understand the benefits and drawbacks of using forced exposure ads.

Overall, the current research shows that judgments about ad interruptions may be changed by manipulating the antecedents of intrusiveness. These findings add to our understanding of how viewers come to define when an ad is intrusive. Furthermore, the research seeks to distinguish the intrusiveness of an advertisement from the consequences of the interruption itself. By demonstrating that intrusiveness is a precursor to feelings of irritation and avoidance behaviors, we have added to the understanding of the underlying mechanism by which negative reactions to advertising occur. By providing this evidence in a single model, we begin to understand how both the antecedents and consequences of forced exposure advertising are best understood by examining the construct of intrusiveness.

\section{References}

Aaker, David S. and Donald E. Bruzzone (1985), "Causes of Irritation in Advertising," Journal of Marketing, 49 (2), 47-57.

Abernethy, Avery M. (1991), "Physical and Mechanical Avoidance of Television Commercials: An Exploratory Study of Zipping, Zapping and Leaving," in Proceedings of the American Academy of Advertising, Rebecca Holman, ed., New York: The American Academy of Advertising, 223-231.

Alwitt, Linda F. and Paul R. Prabhaker (1992), "Functional and Belief Dimensions of Attitudes to Television," Journal of Advertising Research, 32 (5), 30-42.

Bauer, Raymond A and Stephen A. Greyser (1968), Advertising in American: The Consumer View, Boston, MA: Harvard University.

Biel, Alexander L. and Carol A. Bridgwater (1990), "Attributes of Likable Television Commercials," Journal of Advertising Research, 30 (3), 38-44.

Bollen, Kenneth A. (1989), Structural Equations with Latent Variables, New York: John Wiley \& Sons.

Bowen, John (2001), "Analyst View: The Emergence of Rich Media," Red Herring, (January 24), [http:/www.redherring.com/ index.asp?layout=story\&channel $=20000002 \& d o c$ id $=1210017521]$.

Brehm, Jack W. (1966), A Theory of Psychological Reactance, New York: Academic Press.

Brehm, Sharon S. and Jack W. Brehm (1981), Psychological Reactance: A Theory of Freedom and Control, New York: Academic Press.

Clancey, Maura (1994), "The Television Audience Examined," Journal of Advertising Research, 39 (5), 27-37.

Clee, Mona A. and Robert A. Wicklund (1980), "Consumer Behavior and Psychological Reactance," Journal of Consumer Research, $6(4), 389$.

Cronin, John J. and Nancy E. Menelly (1992), "Discrimination vs. Avoidance: 'Zipping' of Television Commercials," Journal of Advertising, 21 (Summer), 1-7.
Ducoffe, Robert H. (1995), "How Consumers Assess the Value of Advertising," Journal of Current Issues and Research in Advertising, 17 (1), 1-18.

(1996), "Advertising Value and Advertising on the Web," Journal of Advertising Research, 36 (5), 21-35.

Friestad, Marian and Peter Wright (1994), "The Persuasion Knowledge Model: How People Cope with Persuasion Attempts," Journal of Consumer Research, 21 (1), 1-31.

$\mathrm{Ha}$, Louisa (1996), "Advertising Clutter in Consumer Magazines: Dimensions and Effects," Journal of Advertising Research, 36 (July/August), 76-83.

Hoffman, Donna L. and Thomas P. Novak (1996), "Marketing in Hypermedia Computer-Mediated Environments: Conceptual Foundations," Journal of Marketing, 60 (3), 50-68.

Interactive Advertising Bureau (2001), Rich Media Ad Unit Guidelines, Interactive Advertising Bureau, (August 6), [http:/ www.iab.net/rich_content/index.html].

Janiszewski, Chris (19990), "The Influence of Nonattended Material on the Processing of Advertising Claims," Journal of Marketing Research, 27 (3), 263-278.

Jöreskog, Karl C. and Dag Sörbom (1989), LISREL 7: A Guide to the Program and Applications, $2 \mathrm{~d}$ ed., Chicago: SPSS Inc.

Kahneman, Daniel (1973), Attention and Effort, Englewood Cliffs, NJ: Prentice Hall.

Kennedy, John R. (1971), "How Program Environment Affects TV Commercials," Joumal of Advertising Research, 11 (1), 33-38.

Krugman, Dean M. and Keith F. Johnson (1991), "Differences in the Consumption of Traditional Broadcast and VCR Movie Rental," Journal of Broadcasting \& Electronic Media, 35 (Spring), 213-232.

Krugman, Herbert E. (1983), "Television Program Interest and Commercial Interruption: Are Commercials on Interesting Programs Less Effective?' Journal of Advertising Research, 23 (1), 21-23.

Li, Hairong, Steven M. Edwards, and Joo-Hyun Lee (2001), "Measuring the Intrusiveness of Internet Advertising: Scale Development and Validation," in Proceedings of the 2001 Conference of the American Academy of Advertising, Charles R. Taylor, ed., Villanova, l'A: American Academy of Advertising, 25-26.

McQuail, Dennis (1983), Mass Communication Theory: An Introduction, Thousand Oaks, CA: Sage.

Milward Brown Interactive (1999a), The Wired Digital Rich Media Study, San Francisco, CA: Millward Brown Interactive, [http:/ www.intelliquest.com/search/results.asp?vpath $=/$ press/releases $/$ mbi_release 05. asp].

- (1999b), Evaluating the Effectiveness of the Superstitials, Millward Brown Interactive, (October), [http: www.unicast.com/downloads/mbi.pdf].

Murry, John P., Jr., John L. Lastovicka, and Surendra N. Singh (1992), "Feeling and Liking Responses to Television Programs: An Examination of Two Explanations for Media Context Effects," Joumal of Consumer Research, 18 (March), 441-451.

Park, C. Whan and Gordon W. McClung (1985), "The Effect of TV Program Involvement on Involvement with Commercials," in Proceedings of Association of Consumer Research, Richard J. Lutz, ed., Las Vegas, NV: Association of Consumer Research, 544-547.

Pasadeos, Yorgo (1990), "Perceived Informativeness of and Irritation with Local Advertising," Joumalism Quarterly, 67 (1), 35-39.

Petty, Richard E. and John T. Cacioppo (1979), "Issue Involvement Can Increase or Decrease Persuasion by Enhancing MessageRelevant Cognitive Responses," Journal of Personality and Social Psychology, 37 (10), 1915-1926.

Reizenstine, Richard C. (1971), "A Dissonance Approach to Measuring the Effectiveness of Two Personal Selling Techniques Through Decision Reversal," Proceedings of the Conference of the American Marketing Association, Chicago: American Marketing Association, 176-180. 
Robertson, Thomas S. and John R. Rossiter (1974), "Children and Commercial Persuasion: An Attribution Theory Analysis," Journal of Consumer Research, 1 (1), 13.

Sandage, Charles H. and John Leckenby (1980), "Student Attitude toward Advertising: Institution vs. Instrument," Journal of Advertising, 9 (2), 29-33.

Sherman, Lee and John Deighton (2001), "Banner Advertising: Measuring Effectiveness and Optimizing Placement," Journal of Interactive Marketing, 15 (2), 60-64.

Singh, Surendra N. and Gilbert A. Churchill Jr. (1987), "Arousal and Advertising Effectiveness," Journal of Advertising, 16 (1), 4-10.

Soldow, Gary F. and Victor Principe (1981), "Response to Commercials as a Function of Program Context," Journal of Advertising Research, 21 (2), 59-65.
Speck, Paul Surgi and Michael T. Elliott (1997), "Predictors of Advertising Avoidance in Print and Broadcast Media," Journal of Advertising, 26 (3), 61-76.

Taylor, Catharine P. (2001), "The Crackle Over 'Pop Unders," Advertising Age, 72 (July 16), 36.

Wells, William D., Clark Leavitt, and Maureen McConville (1971), "A Reaction Profile for TV Commercials," Journal of Advertising Research, 11 (December), 11-17.

Yi, Youjae (1990), "Cognitive and Affective Priming Effects of the Context for Print Advertising," Journal of Advertising, 19 (2), 40-48. 